\title{
PENGARUH INTENSITAS KONSUMSI ENERGI (IKE) DAN AKSES AIR BAGI PRODUK DOMESTIK BRUTO NEGARA-NEGARA ORGANISASI KERJASAMA ISLAM (OKI)1)
}

\author{
Bagus Wilarnugroho \\ Program Studi S1 Ekonomi Islam-Fakultas Ekonomi dan Bisnis-Universitas Airlangga \\ Email : bagus.wilar@gmail.com \\ Sri Herianingrum \\ Departemen Ekonomi Syariah-Fakultas Ekonomi dan Bisnis-Universitas Airlangga \\ Email : sriheria@yahoo.co.id
}

\begin{abstract}
:
Energy use intensity (EUI) and water access are vital to economic activities. World energy need is growing meanwhile the energy resource couldn't follow it. Futhermore, world fresh water quantity is declining. This research is aim to acknowledge whether there is an impact of EUI and water access on gross domestic products (GDP) in Organization of Islamic Cooperation (OIC) member states. The research is using World Bank data with quantitative approach. The data had been running using panel data regression method. The data are from Indonesia, Malaysia, Pakistan and Bangladesh which consist of EUI and water access data as an independent variables and GDP as a dependent varible. According to the results, seen that EUI and water access have a sigificant impact, partialy and simultaneously, to GDP within four OIC member. Therefore, we can conclude that the EUI and water access are able to increase GDPof OIC member states.
\end{abstract}

\section{Keywords: Organization of Islamic Cooperation, Energy Use Intensity, Water Access, Gross DomesticProduct}

\section{PENDAHULUAN}

Kebutuhan energi dunia terus meningkat setiap tahunnya. Hal tersebut dapat dilihat dari meningkatnya permintaan dunia terhadap energi. Berdasarkan data Bank Dunia (2014), konsumsi energi per kapita pada tahun 2013 sebesar 1.894,4 koe $(\mathrm{kg}$ of oil equivalent) meningkat lebih dari 110,2 koe dibandingkan periode yang sama di tahun 2006. Peningkatan kebutuhan energi tersebut, di dominasi oleh konsumsi terhadap bahan bakar fosil, seperti batu bara, minyak bumi, dan gas bumi, yang mendominasi lebih dari 80 \% (Bank Dunia, 2012) bauran konsumsi energi dunia.

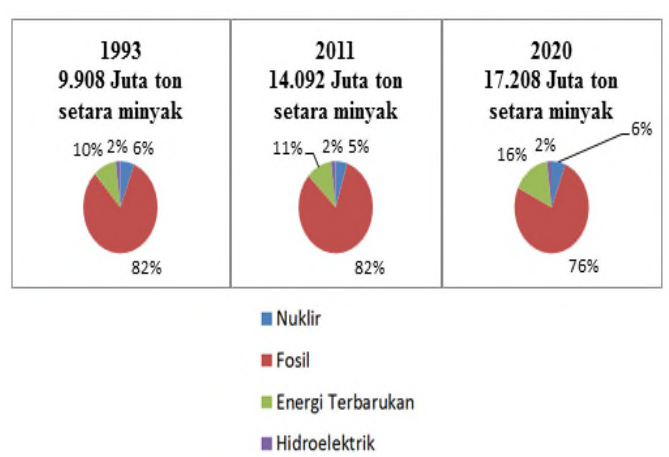

Sumber: Word Energy Council. 2013. World Energy Resources: 2013 Survey Gambar 1.

Bauran energi Dunia

Kuantitas total penggunaan energi juga terlihat meningkat selama tahun 1993 sampai tahun 2011, dari 9.908 juta ton setara minyak pada tahun 1993 menjadi 14.092 juta ton setara minyak pada tahun 2011. Peningkatan pada konsumsi energi

1) Jurnal ini merupakan bagian dari skripsi yang ditulis oleh Bagus Wilarnugroho, NIM: 041211432028 , yang diuji pada 24 Mei 2016 
Wilarnugroho, et al/Jurnal Ekonomi Syariah Teori dan Terapan Vol. 3 No. 12 Desember 2016: 960-972; PENGARUH INTENSITAS KONSUMSI ENERGI (IKE) DAN AKSES AIR BAGI PRODUK DOMESTIK BRUTO NEGARA-NEGARA ORGANISASI KERJASAMA ISLAM (OKI)

global tersebut diprediksi akan terus meningkat sampai tahun 2020 dengan kunatitas mencapai 17.208 juta ton setara minyak.

Hal yang sama juga terjadi pada sumber energi primer dunia lainnya. Batu bara, yang menjadi sumber energi primer kedua terbesar dalam bauran energi dunia. Diperkirakan, cadangan terbukti batu bara dunia adalah sekitar 891.530 juta ton. Cadangan tersebut terus menurun selama periode 1993 sampai 2011 sebesar 14\%. Namun hal tersebut tidak diimbangi dengan konsumsi yang naik terus selama periode yang sama sebesar $68 \%$. Sementara cadangan gas alam dunia hanya sekitar 209.741,9 miliar meter kubik dan diperkirakan hanya dapat bertahan selama 55 tahun ke depan.

Selain itu, harga energi dunia juga selalu berfluktuasi. Hal tersebut diwakili oleh harga minyak yang selalu mengalami fluktuasi selama beberapa dekade. Pada tahun 1972-1974 harga minyak mengalami kenaikan hampir $50 \%$ per tahun dan hal tersebut terus terjadi sampai tahun 1980 dimana harga minyak mencapai 37,42 $\$ /$ barell. Namun kemudian terus turun hingga mencapai level terendahnya di harga 14,87 \$/barell hanya dalam 7 tahun (McMahon, 2015).

Masalah lain yang timbul dari meningkatnya konsumsi energi dunia adalah terkait kelestarian lingkungan. Bahan bakar fosil sebagai sumber energi primer dominan dalam bauran energi melepaskan polusi karbondioksida, sulfur, dan polutan lainnya ke udara. Menjadikan kualitas udara berkurang dan meningkatkan suhu rata-rata dunia. Hal tersebut dapat mengganggu siklus alam yang ada dan menyebabkan kerusakan pada berbagai aspek hidup manusia. Kerusakan yang ditibulkan oleh polusi karbon dapat mencapai $1.1 \%$ dari produk domestik neto (Bank Dunia:2013)

Tidak jauh berbeda, kondisi air layak konsumsi di dunia juga mengkhawatirkan. Walaupun kuantitas air di dunia tidak berkurang, namun jumlah yang dapat dikonsumsi berkurang. Menurut World Water Assesment Programme (WWAP) (2013:6),

"70\% limbah industri di negara berkembang dibuang ke aliran air tanpa melewati proses pengolahan yang semestinya dan mencemari sumber air layak konsumsi."

Sehingga walaupun terdapat sumber air yang memiliki kuantitas yang berlimpah, namun tidak dapat dimanfaatkan karena pencemaran yang terjadi.

Bertambahnya penduduk dunia juga menjadi tantangan dalam mengatasi kondisi air layak konsumsi di dunia. Pada tahun 2050, diprediksi permintaan air akan meningkat sebesar $55 \%$, didorong oleh bertambahnya permintaan air dari sektor industri, pembangkit listrik, serta pemakaian domestik (WWAP, 2015:2). Sampai saat ini, ada sekitar 784 juta orang yang belum memiliki akses ke sumber air yang layak dan permintaan air untuk kepentingan industri diprediksi meningkat sebesar $400 \%$ 
Wilarnugroho, et al/Jurnal Ekonomi Syariah Teori dan Terapan Vol. 3 No. 12 Desember 2016: 960-972; PENGARUH INTENSITAS KONSUMSI ENERGI (IKE) DAN AKSES AIR BAGI PRODUK DOMESTIK BRUTO NEGARA-NEGARA ORGANISASI KERJASAMA ISLAM (OKI)

sepanjang tahun 2000 sampai 2050 (WWAP, 2015:v). Sementara sekitar 20\% cadangan air bawah tanah saat ini dieksploitasi secara berlebihan (WWAP, 2015:2).

Masalah energi dan air yang telah dibahas diatas berpotensi mengganggu produktivitas masyarakat. Terganggunya produktivitas akan mempengaruhi pertumbuhan ekonomi negara. $\mathrm{Hal}$ tersebut didukung oleh pernyataan Connor, dkk dalam WWAP (2015:10):

"... and much of this economic growth has come at a significant social and environmental cost. during this same period, population growth, urbanization, migration and industrialization, along with increases in production and consumption, have generated ever-increasing demands for freshwater resources. these same processes have also contributed to the polluting of water resources, further reducing their immediate accessibility and thus compromising the capacity of ecosystems and the natural water cycle to satisfy the world's growing demand for water."

Allah SWT telah memberikan

tuntunan dalam menyediakan energi dan air dalam mendukung aktivitas muamalah, khususnya perekonomian umat manusia. Selain itu Allah juga mewasiatkan kepada umat muslim untuk berperilaku efisien dalam menggunakan sumber daya. Al Qur'an menjelaskan:

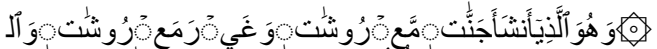

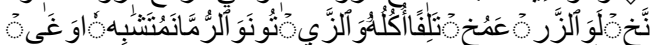

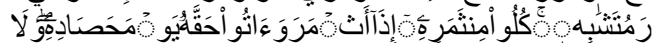

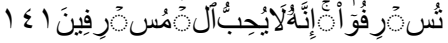

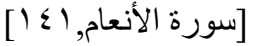

141. "Dan Dialah yang menjadikan kebun-kebun yang berjunjung dan yang tidak berjunjung, pohon korma, tanam-tanaman yang bermacammacam buahnya, zaitun dan delima yang serupa (bentuk dan warnanya) dan tidak sama (rasanya). Makanlah dari buahnya (yang bermacammacam itu) bila dia berbuah, dan tunaikanlah haknya di hari memetik hasilnya (dengan disedekahkan kepada fakir miskin); dan janganlah kamu berlebih-lebihan. Sesungguhnya Allah tidak menyukai orang yang berlebih-lebihan"

(QS Al An'am : 141)

Menurut Ibnu Jarir dalam tafsir Ibnu Katsir (2009:387), maksud dari kalimat "...dan janganlah kamu berlebihlebihan. Sesungguhnya Allah tidak menyukai orang yang berlebih-lebihan." adalah larangan yang berlaku untuk segala sesuatu. Ayat di atas menunjukkan bahwa Allah tidak suka tindakan berlebih lebihan atau bisa dikatakan bahwa Allah mendukung tindakan efisien dalam setiap aspek kehidupan. Begitu pula dengan mengelola penggunaan energi listrik dan air.

Umat Muslim telah diberikan petunjuk berupa kitab yang benar yaitu $\mathrm{Al}$ Qur'an dan sudah sepatutnya untuk melaksanakan apa yang diperintahkan oleh Allah dan menjauhi larangannya. Populasi Umat Muslim dunia saat ini mencapai $23,4 \%$ populasi dunia (Indrawan, Republika 27/5/2015) dan hampir sebagian besar negara-negara Islam menjadi anggota Organisasi Kerjasama Islam (OKI). Sehingga OKI merupakan representasi Kaum Muslimin saat ini.

Berdasarkan Populasi muslim yang besar, pengembangan keilmuan dan penerapan Ekonomi Islam yang maju, serta di dukung oleh ketersediaan data, maka penelitian ini mengamati empat 
Wilarnugroho, et al/Jurnal Ekonomi Syariah Teori dan Terapan Vol. 3 No. 12 Desember 2016: 960-972; PENGARUH INTENSITAS KONSUMSI ENERGI (IKE) DAN AKSES AIR BAGI PRODUK DOMESTIK BRUTO NEGARA-NEGARA ORGANISASI KERJASAMA ISLAM (OKI)

negara OKI yaitu Indonesia, Malaysia, Pakistan, dan Bangladesh, sehingga diharapkan dapat mewakili keadaan intensitas konsumsi energi, akses air, dan produk doestik bruto Kaum Muslimin dunia. Berdasarkan penjabaran di atas, maka rumusan masalah yang diajukan adalah: 1) Apakah terdapat pengaruh secara parsial antara intensitas konsumsi energi dan akses air terhadap produk domestik bruto negara-negara anggota Organisasi Kerjasama Islam? 2) Apakah terdapat pengaruh secara simultan antara intensitas konsumsi energi dan akses air terhadap produk domestik bruto negara-negara anggota Organisasi Kerjasama Islam?

Tujuan penelitian ini adalah: 1) Mengetahui pengaruh antara intensitas konsumsi energi dan akses air secara parsial terhadap produk domestik bruto negara-negara anggota Organisasi Kerjasama Islam, 2) Mengetahui pengaruh antara intensitas konsumsi energi dan akses air secara simultan terhadap produk domestik bruto negara-negara anggota Organisasi Kerjasama Islam.

\section{LANDASAN TEORI}

Pada dasarnya, intensitas konsumsi energi merupakan indikator terhadap besarnya energi yang digunakan untuk memproduksi satu satuan output ekonomi (Bank Dunia: 2014). Intesitas konsumsi energi, menurut Medlock (2007:97), adalah kuantitas energi yang dikonsumsi untuk menghasilkan setiap unit ekonomi. Intensitas konsumsi energi (IKE), menurutnya dihitung dengan membandingkan antara energi yang digunakan dan produk domestik bruto (British Thermal Unit/\$ GDP). Senada dengan dua definsi sebelumnya, Madurerira (2014:153-154), dalam bukunya Key Concepts in Energy, menyatakan bahwa

"Called energy intensity, it describes the ratio between energy consumption (E) and a relevant measure of activity or output (Y)."

Allah memberikan perintah bagi manusia untuk tidak beperilaku boros. Dalam surat Al Isra ayat 27 Allah memerintahkan manusia agar tidak berlebih-lebihan atau boros dalam melakukan segala sesuatu, termasuk dalam menggunakan energi. Jika ingin menghasilkan atau mendapatkan sesuatu hendaknya menggunakan energi secukupnya, tidak berlebih-lebihan sehingga jumlah energi yang berlebih tersebut tidak dapat digunakan oleh pihak lain yang membutuhkan dan menjadi sia-sia.

Q.S Al Isra: 26-27

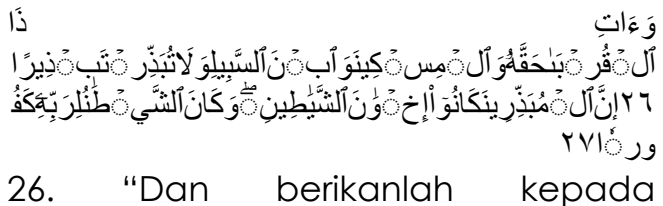
keluarga-keluarga yang dekat akan haknya, kepada orang miskin dan orang yang dalam perjalanan dan janganlah kamu menghamburhamburkan (hartamu) secara boros." 27. "Sesungguhnya pemborospemboros itu adalah saudarasaudara syaitan dan syaitan itu adalah sangat ingkar kepada Tuhannya". (QS Al Isra: 26-27).

Akses air merupakan bagian yang penting dalam menjaga dan mengembangkan ketahanan air. Seperti 
Wilarnugroho, et al/Jurnal Ekonomi Syariah Teori dan Terapan Vol. 3 No. 12 Desember 2016: 960-972; PENGARUH INTENSITAS KONSUMSI ENERGI (IKE) DAN AKSES AIR BAGI PRODUK DOMESTIK BRUTO NEGARA-NEGARA ORGANISASI KERJASAMA ISLAM (OKI)

yang dijabarkan oleh United Nation University, bagian penting dari mencapai dan menjaga ketahanann air adalah: 1) Akses ke sumber air minum yang aman dan cukup dengan harga yang terjangkau untuk memenuhi kebutuhan hidup yang mendasar, termasuk untuk keperluan sanitasi dan kebersihan, serta menjaga kesehatan dan kesejahteraan 2) Pelestarian dan perlindungan terkait penyediaan air yang dibutuhkan oleh ekosistem agar tetap dapat menjalankan fungsinya 3) Menyediakan air untuk kegiatan pengembangan sektor sosial dan ekonomi.

Allah SWT juga menceritakan permasalahan akses air di dalam Al Quran surat Al A'raf ayat 160. Ayat tersebut menggambarkan bagaimana keadaan suku-suku Bani Israil yang memiliki akses ke sumber air yang baik. Allah memberikan mereka rezeki berupa sumber air yang dapat mereka pergunakan untuk kebutuhan mereka tanpa harus bersusah payah mendapatkannya.

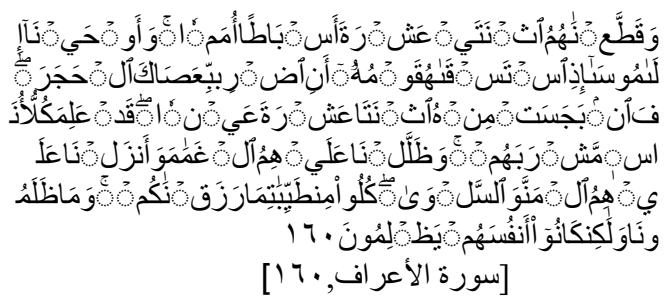

160. "Dan mereka Kami bagi menjadi dua belas suku yang masingmasingnya berjumlah besar dan Kami wahyukan kepada Musa ketika kaumnya meminta air kepadanya: 'Pukullah batu itu dengan tongkatmu!'. Maka memancarlah dari padanya duabelas mata air. Sesungguhnya tiap-tiap suku mengetahui tempat minum masingmasing. Dan Kami naungkan awan di atas mereka dan Kami turunkan kepada mereka manna dan salwa. (Kami berfirman): 'Makanlah yang baik-baik dari apa yang telah Kami rezekikan kepadamu'. Mereka tidak menganiaya Kami, tapi merekalah yang selalu menganiaya dirinya sendiri". (Al A'raf: 160)

Ibnu Katsir

(2009:175-176)-

memberikan penjelasan bahwa ayat ini memilik kesamaan dengan ayat 60 pada surat Al Baqoroh. Allah memberikan banyak nikmat kepada Bani Israil. Salah satunya adalah dengan Akses air yang mudah dan makanan berupa manna dan salwa. Sehingga dengan nikmat tersebut Bani Israil diharapkan dapat bersyukur dan tidak berbuat kerusakan.

Produk domestik bruto, menurut Case dkk (2012:111), adalah

"total harga pasar dari produksi suatu negara. Mencakup nilai pasar dari seluruh barang dan jasa yang diproduksi dalam suatu periode waktu oleh seluruh sektor produksi yang berada dalam negara tersebut".

Sementara menurut Mankiw, dalam bukunya principles of macroeconomics (2012:198), menyatakan bahwa produk domestik bruto adalah:

"nilai pasar dari semua barang dan jasa final yang diproduksi dalam sebuah negara pada periode waktu tertentu."

Medlock (2007:92-94) memberikan penjelasan bahwa struktur ekonomi dan teknologi merupakan penentu bagi permintaan energi. Pada tingkatan makro, keduanya mempengaruhi intensitas konsumsi energi, yaitu kuantitas konsumsi energi per unit produksi dalam ekonomi. Bersamaan dengan perubahan struktur ekonomi, sektor jasa akan semakin mendominasi perekonomian. Sampai 
Wilarnugroho, et al/Jurnal Ekonomi Syariah Teori dan Terapan Vol. 3 No. 12 Desember 2016: 960-972; PENGARUH INTENSITAS KONSUMSI ENERGI (IKE) DAN AKSES AIR BAGI PRODUK DOMESTIK BRUTO NEGARA-NEGARA ORGANISASI KERJASAMA ISLAM (OKI)

pada batas di mana satu unit produk jasa membutuhkan lebih sedikit energi dibandingkan satu unit produk manufaktur, sehingga intensitas konsumsi energi akan menurun. Adapun terkait teknologi, dengan semakin banyaknya penggunaan modal di sektor yang efisien energi, maka kebutuhan energi untuk satu satuan unit produksi akan menurun, dan membuka jalan bagi perekonomian untuk terus berkembang tanpa meningkatkan kebutuhan energi.

$$
\text { Madureira }
$$
mengatakan"Kiranya, suatu negara akan menjadi lebih efisien jika telah melewati suatu fase tingkat pendapatan tertentu". Selama sektor pertanian mendominasi aktivitas ekonomi, total energi komersial akan dikonsumsi oleh sektor rumah tangga untuk memenuhi kebutuhan dasar seperti memasak dan mengatur suhu ruangan. Lalu, ketika aktivitas produksi beranjak menuju sektor yang lebih tinggi intensitas energinya maka intensitas konsumsi energi akan meningkat. Dengan bergeraknya perekonomian ke sektor yang lebih rendah konsumsi energinya seperti sektor jasa maka intensitas konsumsi energi akan berbalik dan mulai menurun.

$$
\text { Menurut Stockholm International }
$$
Water Institute (2005:11), sektor ekonomi masyarakat, termasuk pertanian, industri dan jasa, sangat bergantung kepada air. Lebih lanjut, Stockholm International Water Institute (SIWI) mengatakan,

"Terdapat hubungan positif antara
peningkatan pendapatan nasional
dan proporsi masyarakat dengan akses
ke sumber air yang baik. Bisa dikatakan bahwa hubungan antara penyediaan sumber air yang lebih baik dan pertumbuhan ekonomi adalah saling memperkuat satu sama lain".

Akses ke sumber air bersih akan meningkatkan taraf kesehatan masyarakat, seperti berkurangnya kasus tifus maupun diare. Menurut Huton dan Haler dalam Banerjee dan Morella (201 1:12), dengan berkurangnya angka infeksi diare akan menghasilkan peningkatan 99 juta jam belajar di sekolah dan 456 juta jam kerja bagi para pekerja. Keuntungan yang dihasilkan dari peningkatan jam kerja sendiri akan menghasilkan keuntungan ekonomi sebesar 116 juta dollar.

Berdasarkan penjelasan di atas, maka hipotesis yang diajukan adalah sebagai berikut:

$\mathrm{H}_{1}$ : Diduga Intensitas Konsumsi Energi (IKE) dan akses air bersih berpengaruh secara parsial tehadap PDB di negara-negara anggota Organisasi Kerjasama Islam (OKI) selama tahun 1990-2012.

$\mathrm{H}_{2}$ : Diduga Intensitas Konsumsi Energi (IKE) dan akses air bersih berpengaruh secara simultan tehadap PDB di negara-negara anggota Organisasi Kerjasama Islami (OKI) selama tahun 1990-2012.

Penelitian ini menggunakan model analisis untuk mencari korelasi antara variabel independen terhadap variabel dependen. Intensitas konsumsi energi (IKE) dan akses air sebagai variabel independen diamati hubungan korelasinya terhadap produk domestik 
Wilarnugroho, et al/Jurnal Ekonomi Syariah Teori dan Terapan Vol. 3 No. 12 Desember 2016: 960-972; PENGARUH INTENSITAS KONSUMSI ENERGI (IKE) DAN AKSES AIR BAGI PRODUK DOMESTIK BRUTO NEGARA-NEGARA ORGANISASI KERJASAMA ISLAM (OKI)

bruto (PDB) negara-negara anggota Organisasi Kerjasama Islam (OKI) sebagai varibael independen. Penelitian ini menggunakan regresi data panel dengan model analisis sebagai berikut:

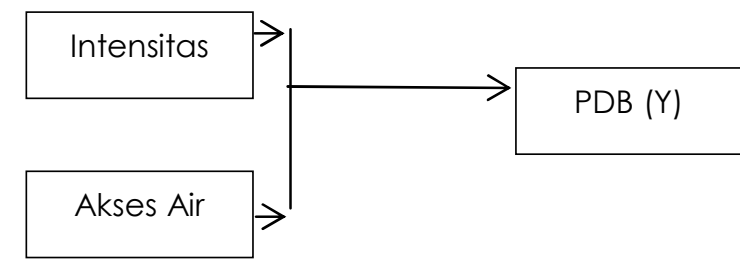

Gambar 2.

Metode Analisis

$Y=\beta_{0}+\beta_{1} X_{1}+\beta_{2} X_{2}+\mu$

$\mathrm{Y}=$ Produk Domestik Bruto (PDB)

$\mathrm{X}_{1} \quad=$ Intensitas Konsumsi Energi

$\mathrm{X}_{2}=$ Prosenstase Populasi yang memiliki akses ke sumber air bersih yang layak

$\beta_{0}=$ konstanta

$\beta_{1}-\beta_{2}=$ koefisien masing-masing variabel independen

$\mu \quad=$ error term

\section{METODE PENELITIAN}

\section{Pendekatan penelitian}

Penelitian ini menggunakan metodologi penelitian kuantitatif. Penelitian kuantitatif merupakan penelitian yang terstruktur dan mengkuantifikasikan data untuk dapat digeneralisir (Anshori, 2009:13). Data yang digunakan dalam penelitian ini adalah data sekunder yang terdiri dari Intensitas konsumsi energi (IKE), Akses air, dan produk domestik bruto (PDB) pada empat negara Organisasi Kerjasama Islam (OKI), yaitu Indonesia, Malaysia, Pakistan, dan Bangladesh.

Penelitian ini mencoba meneliti pengaruh intensitas konsumsi energi dan akses air terhadap pendapatan domestik bruto (PDB) di empat negara anggota OKI yaitu Indonesia, Malaysia, Paksitan, Bangladesh selama periode 1990 sampai 2012. Data IKE, akses air, dan PDB dari ke empat negara tersebut akan diuji sesuai hipotesis yang diajukan sehingga dapat diambil kesimpulan yang dapat digeneralisir.

\section{Definisi Operasional}

Untuk memberikan penjelasan terhadap variabel-variabel yang digunakan di dalam penelitian ini, maka variabel-variabel tersebut didefinisikan:

\section{PDB (Y)}

Produk Domestik Bruto merupakan jumlah total nilai tambah barang dan jasa yang dihasilkan oleh seluruh penduduk dalam perekonomian suatu negara ditambah pajak dan dikurangi subsidi. PDB diperhitungkan tanpa melakukan pemotongan terhadap nilai depresiasi aset atau terhadap degrdasi sumber daya alam Semua perhitungan menggunakan nilai dollar tetap pada tahun 2011 dengan mempertimbangkan paritas daya beli. Data dikumpulkan dari empat negara anggota OKI yaitu Indonesia, Malaysia, Pakistan, dan Bangladesh mulai dari tahun 1990 sampai 2012. 
Wilarnugroho, et al/Jurnal Ekonomi Syariah Teori dan Terapan Vol. 3 No. 12 Desember 2016: 960-972; PENGARUH INTENSITAS KONSUMSI ENERGI (IKE) DAN AKSES AIR BAGI PRODUK DOMESTIK BRUTO NEGARA-NEGARA ORGANISASI KERJASAMA ISLAM (OKI)

\section{Intensitas Konsumsi Energi $\left(\mathrm{X}_{1}\right)$}

Intensitas Konsumsi Energi (IKE) adalah rasio antara pasokan energi dan PDB yang dihitung dengan memperhatikan paritas daya beli (MJ/\$2011 PPP GDP). IKE merupakan indikator untuk melihat seberapa bayak energi yang digunakan untuk menghasilkan satu unit output ekonomi. Semua perhitungan menggunakan nilai dollar tetap pada tahun 2011 dengan mempertimbangkan disparitas daya beli. Data dikumpulkan dari empat negara anggota OKI yaitu Indonesia, Malaysia, Pakistan, dan Bangladesh mulai dari tahun 1990 sampai 2012.

\section{Akses Air ( $\left.\mathrm{X}_{2}\right)$}

Akses air mengacu pada presentasi populasi yang memiliki akses untuk mendapatkan air bersih yang layak minum. Akses air ke sumber yang layak meliputi ketersediaan jaringan pipa untuk menyalurkan air sampai ke rumah penduduk atau bentuk lain yang memungkinkan penduduk untuk menjangkau sumber air bersih yang layak. Data dikumpulkan dari empat negara anggota OKI yaitu Indonesia, Malaysia, Pakistan, dan Bangladesh mulai dari tahun 1990 sampai 2012.

\section{Jenis dan Sumber Data}

Jenis data yang digunakan dalam penelitian ini adalah data sekunder. Data sekunder yang digunakan dalam penelitian ini berasal dari data yang dipublikasikan oleh Bank Dunia melalui websitenya worldbank.org. Data tersebut akan dibentuk menjadi data panel, yaitu dengan menggabungkan data yang bersifat time series dan cross section.

\section{Populasi}

Anshori dan Iswati (92: 2009) mengatakan bahwa populasi merupakan wilayah generalisasi yang mempunyai kualitas dan karakteristik tertentu yang ditetapkan oleh peneliti untuk dipelajari dan kemudian ditarik kesimpulannya. Kriteria populasi dalam penelitian ini adalah negara-negara yang tergabung dalam Organisasi Kerjasama Islam (OKI).

\section{Sampel}

Anshori dan Iswati (2009:94) mengatakan bahwa sampel merupakan bagian dari jumlah dan karakteristik yang dimiliki oleh populasi. Sehingga dapat disimpulkan, sampel adalah kumpulan dari objek penelitian atau populasi yang diamati oleh peneliti. Penelitian ini menggunakan sampel yang terdiri dari empat negara anggota Organisasi Kerjasama Islam yaitu Indonesia, Malaysia, Pakistan, dan Bangladesh karena:

1. Merupakan negara anggota Organisasi Kerjasama Islam dengan populasi muslim yang besar.

2. Merupakan negara yang tergolong maju dalam mengembangkan ekonomi islam, baik dari sisi pengetahuan maupun praktiknya. Malaysia dan Pakistan memilik salah satu dari beberapa universitas terbaik untuk mempelajari ekonomi islam yaitu International Islamic University of Malaysia dan International University of Pakistan. Selain itu beberapa pemikir ekonomi Islam juga berasal 
Wilarnugroho, et al/Jurnal Ekonomi Syariah Teori dan Terapan Vol. 3 No. 12 Desember 2016: 960-972; PENGARUH INTENSITAS KONSUMSI ENERGI (IKE) DAN AKSES AIR BAGI PRODUK DOMESTIK BRUTO NEGARA-NEGARA ORGANISASI KERJASAMA ISLAM (OKI)

dari ke empat negara tersebut seperti Muhammad Abdul Mannan dari Bangladesh, Umer Chapra dari pakistan, Syafii Antonio dan Adiwarman Karim dari Indonesia, serta Ahmed Kameel Mydin Meera dan Abdul Ghafar Islmail dari Malaysia.

3. Selain itu, ke empat negara terseebut memiliki riwayat intensitas konsumsi energi (IKE) dan akses air yang lengkap selama periode 1990 sampai 2012.

\section{Teknik Analisis}

Penelitian ini menggunakan regresi data panel. Berikut merupakan langkahlangkah yang diambil untuk melakukan analisis dalam penelitian ini:

1. Menentukan model regresi data panel. Model data panel yang dapat digunakan adalah Pooled Least Sequare (PLS), Fixed Effect Model (FEM), dan Random Effect Model (REM).

2. Menetukan Model yang digunakan dengan melakukan Uji Chow dan Uji Haussman. Uji Chow digunakan untuk memilih model yang akan digunakan anatara model PLS atau FEM, sementara uji Haussman digunakan untuk memilih model FEM atau REM

3. Uji Hippotesis dengan menggunakan uji † untuk melihat apakah variabel independen secara parsial mempengaruhi variabel dependen. Setelah itu dilanjutkan dengan uji $F$ untuk melihat apakah variabel independen secara simultan mempengaruhi variabel dependen.

4. Uji Statistik koefisien determinasi $\left(R^{2}\right)$ menggambarkan besarnya proporsi variasi dalam variabel terikat, yang dapat dijelaskan atau dipengaruhi oleh variabel independen secara simultan $\left(R^{2}\right)$ maupun parsial $\left(r^{2}\right)$, serta untuk melihat ketepatan garis regresi dan mengukur kemampuan model dalam menjelaskan perubahan variabel dependennya.

\section{HASIL PENELITIAN DAN PEMBAHASAN}

\section{Pemilihan Model}

Tedapat tiga model yang digunakan untuk melakukan estimasi terhadap data panel, yaitu pooled least square (PLS), fixed effect model (FEM), dan random effect model (REM). Penentuan model estimasi dilakukan dengan menggunakan dua bentuk uji, yaitu uji Chow dan uji Haussman. Uji Chow dilakukan untuk memutuskan model mana yang paling tepat digunakan antara model PLS dan FEM. Sementara uji Haussman digunakan untuk memutuskan model mana yang paling tepat antara FEM dan REM. Hasil uji Chow dapat dilihat sebagai berikut:

\begin{tabular}{||lcrr||}
\hline \hline $\begin{array}{l}\text { Redundant Fixed Effects Tests } \\
\text { Equation: UJI_F } \\
\text { Test cross-section fixed effects }\end{array}$ & & & \\
\hline \hline Effects Test & Statistic & d.f. & Prob. \\
\hline \hline Cross-section F & 437.963028 & $(3,86)$ & 0.0000 \\
Cross-section Chi-square & 256.661691 & 3 & 0.0000 \\
\hline \hline & & & \\
\hline
\end{tabular}

Gambar 3.

Uji Chow

Berdasarkan hasil uji Chow pada

gambar 4.1 diperoleh nilai probabulitas 
Wilarnugroho, et al/Jurnal Ekonomi Syariah Teori dan Terapan Vol. 3 No. 12 Desember 2016: 960-972; PENGARUH INTENSITAS KONSUMSI ENERGI (IKE) DAN AKSES AIR BAGI PRODUK DOMESTIK BRUTO NEGARA-NEGARA ORGANISASI KERJASAMA ISLAM (OKI)

sebesar 0,000 . Nilai probabilitas crossection $\mathrm{F}$ lebih kecil dibanding nilai a sebesar 0,05. Maka $\mathrm{H}_{0}$ ditolak dan menerima $H_{1}$, sehingga dapat diambil keputusan menerima $\mathrm{H}_{1}$ dan menggunakan model FEM.

Langkah selanjutnya adalah dengan memilih model yang tepat antara model FEM dan REM. Untuk mengambil keputusan tersebut digunakan uji Haussman. Hasil uji Haussman adalah sebagai berikut:

\begin{tabular}{||lrrr||}
\hline $\begin{array}{l}\text { Correlated Random Effects - Hausman Test } \\
\text { Equation: Untitled } \\
\text { Test cross-section random effects }\end{array}$ & & & \\
\hline \hline Test Summary & Chi-Sq. Statistic & Chi-Sq. d.t. & Prob. \\
\hline \hline Cross-section random & 872.523792 & 2 & 0.0000 \\
\hline \hline
\end{tabular}

Gambar 4.

Uji Hausmann

Berdasarkan hasil uji Haussman pada gambar 4.2 diperoleh nilai probabilitas sebesar 0,000 . Nilai probabilitas crossection random lebih kecil dibanding nilai a sebesar 0,05. Maka $\mathrm{H}_{0}$ ditolak dan $\mathrm{H}_{1}$ diterima, sehingga dapat diambil keputusan menerima $\mathrm{H}_{1}$ dan tetap menggunakan model FEM. Berdasarkan uji chow dan uji haussman, diperoleh kesimpulan bahwa model yang paling tepat untuk melakukan estimasi adalah dengan menggunakan fixed effect model (FEM).

\section{Uji Signifikansi}

Nilai t hitung dari masing-masing variabel independen diperoleh dari estimasi regresi data panel yang ditampilkan pada gambar 4.4. Identifikasi nilai $\dagger$ hitung untuk setiap variabel independen adalah sebagai berikut:
1. Variabel intensitas konsumsi energi (IKE) memiliki nilai propabilitas † hitung sebesar 0,0006. Nilai probabilitas tersebut signifikan pada tingkat kepercayaan sebesar $a=5 \%(0,05)$. Sehingga dapat disimpulkan variabel IKE berpengaruh signifikan secara parsial terhadap PDB.

2. Variabel akses air memiliki nilai probablitas $t$ hitung sebesar 0.000 . Nilai probabilitas tersebut signifikan pada tingkat kepecayaan a sebesar $5 \% \quad(0,05)$. Sehingga dapat disimpulkan variabel akses air berpengaruh signifikan secara parsial terhadap PDB.

Setelah dilakukan pengujian hipotesis dengan menggunakan model FEM pada Eviews 6, maka didapatkan persamaan model regresi sebagai berikut: $Y=\beta_{0}+\beta_{1} X_{1}+\beta_{2} X_{2}+\mu$

$$
\begin{aligned}
Y= & (-2.20 \mathrm{E}+12)-(1.71 \mathrm{E}+11) \mathrm{X}_{1}+ \\
& (4.18 \mathrm{E}+10) \mathrm{X}_{2}+\mu \\
& \text { Koefisiensi dari masing-masing }
\end{aligned}
$$
variabel diinterpretasikan sebagai berikut:

1. Nilai konstanta sebesar $-2.02 E+12$ menunjukkan apabila variabel intensitas konsumsi energi dan akses air bernilai nol atau konstan, maka nilai produk domestik bruto adalah 2.02E+12. Sehingga jika IKE dan akses air bernilai nol maka PDB berpotensi berkurang sebesar $-2.02 \mathrm{E}+12$.

2. Koefisien $X_{1}$ sebesar $-1.71 E+11$. Koefisien parameter untuk variabel intesitas konsumsi energi (IKE) bertanda negatif, hal tersebut menunjukkan bahwa IKE berpengaruh 
Wilarnugroho, et al/Jurnal Ekonomi Syariah Teori dan Terapan Vol. 3 No. 12 Desember 2016: 960-972; PENGARUH INTENSITAS KONSUMSI ENERGI (IKE) DAN AKSES AIR BAGI PRODUK DOMESTIK BRUTO NEGARA-NEGARA ORGANISASI KERJASAMA ISLAM (OKI)

negatif terhadap PDB, jika nilai IKE mengalami kenaikan maka PDB akan menurun dan begitu pula sebaliknya. Setiap kenaikan satu unit IKE akan menyebabkan PDB menurun sebesar $1.71 \mathrm{E}+11$.

3. Koefisien $\mathrm{X}_{2}$ sebesar $4.18 \mathrm{E}+10$. Koefisien parameter untuk variabel akses air bertanda positif, hal tersebut menunjukkan bahwa akses air berpengaruh positif terhadap PDB, jika nilai akses air mengalami kenaikan maka PDB akan meningkat dan begitu pula sebaliknya. Setiap kenaikan satu unit akses air akan menyebabkan PDB meningkat sebesar $4.8 \mathrm{E}+10$.

\begin{tabular}{||crrrr|}
\hline \multicolumn{1}{|l}{ Dependent Variable: GDP } & & & \\
Method: Panel Least Squares & & & \\
Date: 03/02/16 Time: $13: 32$ & & & \\
Sample: 1990 2012 & & & \\
Periods included: 23 & & & \\
Cross-sections included: 4 & & & \\
Total panel (balanced) observations: 92 & & & \\
\hline \hline Variable & Coefficient & Std. Error & t-Statistic & Prob. \\
\hline \hline C & $-2.02 \mathrm{E}+12$ & $5.04 \mathrm{E}+11$ & -3.997388 & 0.0001 \\
IKE & $-1.71 \mathrm{E}+11$ & $4.78 \mathrm{E}+10$ & -3.582390 & 0.0006 \\
WATER PERSEN & $4.18 \mathrm{E}+10$ & $4.08 \mathrm{E}+09$ & 10.23621 & 0.0000 \\
\hline \hline
\end{tabular}

Gambar 5.

Uji $\dagger$

Uji $F$ digunakan untuk menguji hipotesis apakah secara simultan variabel independen mempunyai pengaruh yang signifikan terhadap variabel dependen. Pengujian dilakukan dengan memperhatikan nilai probabilitas F. Hasil estimasi pada gambar 4.5 menunjukkan nilai probabilitas $F$ sebesar 0,000 . Nilai probabilitas $F$ ini lebih kecil dari nilai $a=$ $5 \%$,. Maka dapat ditarik kesimpulan bahwa variabel IKE dan akses air berpengaruh signifikan secara bersamasama terhadap variabel PDB.

\begin{tabular}{||lrll||}
\hline \hline Cross-section fixed (dummy variables) & \\
\hline \hline R-squared & 0.939358 & Mean dependent var & $6.52 \mathrm{E}+11$ \\
Adjusted R-squared & 0.935833 & S.D. dependent var & $5.14 \mathrm{E}+11$ \\
S.E. of regression & $1.30 \mathrm{E}+11$ & Akaike info criterion & 54.08655 \\
Sum squared resid & $1.46 \mathrm{E}+24$ & Schwarz criterion & 54.25101 \\
Log likelihood & -2481.981 & Hannan-Quinn criter & 54.15293 \\
F-statistic & 266.4328 & Durbin-Watson stat & 0.086237 \\
Prob(F-statistic) & 0.000000 & & \\
\hline \hline
\end{tabular}

\section{Gambar 6.}

Uji $f$

- Fakta ini sesuai dengan teori yang diajukan oleh Madureira (2014:154) yang mengatakan bahwa negara-negara cenderung untuk menjadi lebih efisien setelah melewati tingkat pendapatan tertentu. Hal tersebut dapat terjadi karena ada beberapa perubahan dalam struktur aktivitas ekonomi negara, seperti pada perubahan pilihan konsumen, peruahan komposisi bauran energi, dan, lebih jauh, melalui peningkatan efisiensi thermodinamic yang dicapai dengan memenuhi kaidah skala ekonomi, meningkatkan kemampuan mesin, inovasi teknologi, dan mengurangi kebocoran dalam distribusi.

Madureira (2014:154), lebih lanjut menyatakan bahwa sejak akhir perang dunia ke dua, para ahi ekonomi telah menemukan kenyataan bahwa negara maju menunjukkan siklus dengan dua pola yang sangat jelas, yaitu peningkatan intensitas konsumsi energi pada tahap awal industralisasi dan diikuti oleh penurunan yang landai setelah periode tersebut telah matang.

Penurunan nilai intensitas konsumsi energi yang terjadi seiring dengan meningkatnya PDB disebabkan 
Wilarnugroho, et al/Jurnal Ekonomi Syariah Teori dan Terapan Vol. 3 No. 12 Desember 2016: 960-972; PENGARUH INTENSITAS KONSUMSI ENERGI (IKE) DAN AKSES AIR BAGI PRODUK DOMESTIK BRUTO NEGARA-NEGARA ORGANISASI KERJASAMA ISLAM (OKI)

oleh satu atau beberapa faktor berikut, diantaranya, privatisasi, liberalisasi harga, restrukturisasi industri. Sementara menurut Markandya, dkk (2005:123) makin tinggi peningkatan PDB suatu negara maka akan makin cepat menuju tingkat intensitas konsumsi energi yang rendah.

Fakta ini sesuai dengan teori yang diajukan oleh Stockholm Water Institute (2005:11) Sektor ekonomi masyarakat, termasuk pertanian, industri dan jasa, sangat bergantung kepada air. Meningkatkan akses ke pelayanan air dan memperbaiki manajemen sumber air akan secara mendasar berpengaruh kepada pertumbuhan ekonomi melalui bertambah dan berkembangnya produktivitas bisnis. Hal tersebut juga akan memperbaiki taraf kesehatan, produktivitas dan martabat masyarakat secara signifikan. Terdapat hubungan positif antara peningkatan pendapatan nasional dan proporsi masyarakat dengan akses ke sumber air yang baik. Bisa dikatakan bahwa hubungan antara penyediaan sumber air yang lebih baik dan pertumbuhan ekonomi adalah saling memperkuat satu sama lain.

Laporan yang dikeluarkan oleh Stockholm International of Water Institute (2005:4) mengungkapkan bahwa diantara negara-negara terbelakang, negara dengan akses ke sumber air layak konsumsi dan sanitasi yang lebih baik, mengalami pertumbuhan ekonomi yang lebih baik. Negara miskin dengan akses air layak konsumsi yang telah diperbaiki menikmati pertumbuhan ekonomi ratarata 3,7 persen (SIWI, 2005:4).

\section{SIMPULAN}

Berdasarkan hasil dan pembahasan yang telah dijelaskan pada bab sebelumnnya, maka dapat diambil kesimpulan bahwa intensitas konsumsi energi (IKE) berpengaruh negatif signifikan secara parsial terhadap produk domestik bruto (PDB) pada empat negara OKI yang diamati selama periode 1990 sampai 2012. Sementara akses air berpengaruh positif signifikan secara parsial terhadap produk domsetik bruto (PDB) pada empat negara OKI yang diamati selama periode 1990 sampai 2012. Selain itu, Intensitas konsumsi energi (IKE) dan akses air berpengaruh signifikan secara simultan terhadap produk domestik bruto (PDB) pada empat negara OKI yang diamati selama periode 1990 sampai 2012.

Saran yang direkomendasikan setelah melakukan penelitian pengaruh intensitas konsumsi energi (IKE) dan akses air terhadap pendapatan domestik bruto (PDB) adalah sebagai berikut:

1. Perlu adanya kebijakan untuk mendorong efisiensi energi.

2. Memperbaiki pencatatan IKE dan akses air.

3. Membuka akses air yang lebih luas bagi masyarakat

4. Memperkaya variabel untuk mengukur permasalahan air.

\section{DAFTAR PUSTAKA}

Alu Syaikh, Abdullah bin Muhammmad bin Abdurrahman. Tanpa Tahun. Tafsir Ibnu Katsir. Terjemahan oleh $M$ Abdul 
Wilarnugroho, et al/Jurnal Ekonomi Syariah Teori dan Terapan Vol. 3 No. 12 Desember 2016: 960-972; PENGARUH INTENSITAS KONSUMSI ENERGI (IKE) DAN AKSES AIR BAGI PRODUK DOMESTIK BRUTO NEGARA-NEGARA ORGANISASI KERJASAMA ISLAM (OKI)

Ghoffar. 2009. Jakarta: Pustaka Imam Asy Syafi'i

Anshori, Muslich dan Sri Iswati. 2009. Buku Ajar Metodologi Penelitian Kuantitatif. Surabaya: Airlangga University Press

Banerjee, Sudeshna Ghosh. 2011. The Elusiveness of The Millennium Development Goal for Water and Sanitation. dalam buku Sudesha Ghosh Benarjee dan Elvira Morella (ed). Africa's Water and Sanitation Infrastructure: Access, Affordability, and Alternatives. Washington DC: Worldbank

Bank Dunia. 2013. Adjusted savings: carbon dioxide damage (\% of $\mathrm{GNI}$ ), (Online),

(http://data.worldbank.org/indicator/N Y.ADJ.DCO2.GN.ZS, diakses 14 Februari 2016)

---------. 2014. Energy intensity level of primary energy (MJ/\$2011 PPP GDP), (Online),

(http://data.worldbank.org/indicator/E

G.EGY.PRIM.PP.KD?page=4, diakses 14 Februari 2016)

-.-. 2014. Energy use $(\mathrm{kg}$ of oil equivalent per capita), (Online), (http://data.worldbank.org/indicator/E G.USE.PCAP.KG.OE, diakses 14 Februari 2016)

2014. Fossil fuel energy consumption (\% of total), (Online), (http://data.worldbank.org/indicator/E G.USE.COMM.FO.ZS/countries, diakses 14 Februari 2016) 2014. Improved water source (\% of population with access), (Online), (http://data.worldbank.org/indicator/N Y.GDP.MKTP.PP.KD? display=graph, diakses 14 Februari 2016)

-. 2016. GDP, PPP (constant (http://data.worldbank.org/indicator/N Y.GDP.MKTP.PP.KD? display=graph, diakses 14 Februari 2016)

Case, Karl E dkk. 2012. Principles of Macroeconomics. Edisi kesepuluh. Boston: Pearson

Indrawan, Angga. 2015. Inilah 10 Negara dengan Populasi Muslim Terbesar di Dunia, (Online), (http://khazanah.republika.co.id/berita /dunia-islam/islamnusantara/15/05/27/noywh5-inilah-10negara-dengan-populasi-muslim- terbesar-di-dunia, diakses 14 Februari 2016)

Madureira, Nuno Luis. 2014. Key Concepts in Energy. New York: Spinger

Mankiw, N. Gregory. 2012. Principles of Macroeconomics. Edisi ke-enam. Mason: Cengage learning

McMahon, Tim. 2015. Historical Crude Oil Price, (Online), (http://inflationdata.com/Inflation/Inflat ion_Rate/Historical_Oil_Prices_Table.asp, diakses 16 Oktober 2015)

Medlock Kenneth B. 2007. Energy Demand Theory. dalam buku Joanne Evans dan Lester C. Hunt (eds). International Handbook on The Economics of Energy. Cheltenham: Edward Elgar

---------. 2007.The Economics of Energy Supply. Dalam buku Joane Evans dan Lester C. Hunt (ed). International Handbook On The Economics Of Energy. Cheltenham: Edward Elgar Publishing Limited

Prasetiantono, A. Tony. 2014. Revolusi Energi Telah Tiba, (Online), (http://bisniskeuangan.kompas .com/read/2014/12/15/181900926/Revo lusi.Energi.Telah.Tiba, diakses 14 Februari 2016)

Stockholm International Water Institute. 2005. Making Water A Part Of Economic Development: The Economic Benefits of Improved Water Management and Service. Pemerintah Negara Norwegia dan Swedia

WWAP (United Nations World Water Assesment Programe). 2015. The United Nations World Water Development Report 2015: Water For Sustainable World. Paris: UNESCO 